\title{
Microarray gene expression profiling of neural tissues in bovine spastic paresis
}

\author{
Lorraine Pariset ${ }^{1}$, Silvia Bongiorni ${ }^{1}$, Susana Bueno ${ }^{2}$, Cesare EM Gruber ${ }^{1}$, Gianluca Prosperini $^{2}$, Giovanni Chillemi $^{2}$, \\ Silvia Bicorgna', Arcangelo Gentile ${ }^{3}$ and Alessio Valentini ${ }^{1^{*}}$
}

\begin{abstract}
Background: Bovine Spastic Paresis (BSP) is a neuromuscular disorder which affects both male and female cattle. BSP is characterized by spastic contraction and overextension of the gastrocnemious muscle of one or both limbs and is associated with a scarce increase in body weight. This disease seems to be caused by an autosomal and recessive gene, with incomplete penetration, although no genes clearly involved with its onset have been so far identified. We employed cDNA microarrays to identify metabolic pathways affected by BSP in Romagnola cattle breed. Investigation of those pathways at the genome level can help to understand this disease.
\end{abstract}

Results: Microarray analysis of control and affected individuals resulted in 268 differentially expressed genes. These genes were subjected to KEGG pathway functional clustering analysis, revealing that they are predominantly involved in Cell Communication, Signalling Molecules and Interaction and Signal Transduction, Diseases and Nervous System classes. Significantly enriched KEGG pathway's classes for the differentially expressed genes were calculated; interestingly, all those significantly under-expressed in the affected samples are included in Neurodegenerative Diseases. To identify genome locations possibly harbouring gene(s) involved in the disease, the chromosome distribution of the differentially expressed genes was also investigated.

Conclusions: The cDNA microarray we used in this study contains a brain library and, even if carrying an incomplete transcriptome representation, it has proven to be a valuable tool allowing us to add useful and new information to a poorly studied disease. By using this tool, we examined nearly 15000 transcripts and analysed gene pathways affected by the disease. Particularly, our data suggest also a defective glycinergic synaptic transmission in the development of the disease and an alteration of calcium signalling proteins. We provide data to acquire knowledge of a genetic disease for which literature still presents poor results and that could be further and specifically analysed in the next future. Moreover this study, performed in livestock, may also harbour molecular information useful for understanding human diseases.

\section{Background}

The Bovine Spastic Paresis (BSP) is a neuromuscular disorder known since the twenties of past century, affecting both males and females. BSP is characterized by an overextension of the gastrocnemious muscle and linked to a scarce increase in body weight [1]. Although the genes involved have not been identified so far, the current hypothesis is that the disease is due a single autosomal recessive mutation with incomplete penetrance [2]. The BSP symptoms are similar to those of human hyperekplexia

\footnotetext{
*Correspondence: alessio@unitus.it

${ }^{1}$ Department for Innovation in Biological, Agro-food and Forest systems (DIBAF), University of Tuscia, via S. Camillo de Lellis S.n.c, Viterbo, 01100, Italy Full list of author information is available at the end of the article
}

(OMIM ID \#149400), a disease caused by mutations in genes encoding glycinergic proteins (GLRA1, OMIM ID \#138491; SLC6A5, OMIM ID \# 604159; GLRB, OMIM ID \#138492; GPHN, OMIM ID \#603930; ARHGEF9, OMIM ID \#300429). Besides the economic importance in agriculture, BSP may therefore constitute a model also for the human disease.

We studied BSP in Romagnola cattle breed, which presents the disease with a frequency of $0.6 \%$ [2]. Since BSP is reported to be associated to the nervous system [3,4], we performed a microarray analysis on cDNA obtained from spinal cord of normal and affected cattle, in order to identify metabolic pathways associated with the disease. The aim of this study was to detect variations in

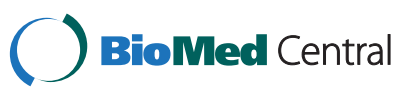


gene pathways by correlating gene expression profiles of healthy and affected animals and to spot genome regions where genes responsible for the disease are more likely to map. This can help in pinpointing a number of genes potentially involved in the disease, providing suitable data for a future gene scan approach.

\section{Methods}

\section{Samples}

Samples of spinal cord of affected and control individuals of Romagnola breed, males and females, were collected from C6 to L6 immediately after slaughtering and later stored in RNA (Sigma-Aldrich). We expected to find most of the genes involved in the spinal cord, being the disease linked to the nervous system $[3,4]$. The experimental work was approved by the Animal Ethics Committee of CRA, Italy, in accordance with local ethical requirements. Total RNA was extracted from $250 \mu \mathrm{g}$ tissue samples by homogenization in QIAzolLysis Reagent (Qiagen) and according to RNeasy Lipid kit (Qiagen) protocol. After purification, RNA integrity was determined spectroscopically (GeneQuantpro, Amersham Pharmacia Biotech) and by gel electrophoresis. Only RNA with A260/280 and A260/230 ratios above 1.8 was used for amplification. RNA was quantified using a DTX 800 Multimode Detector (Beckman Coulter) using quant-it kit (Invitrogen). For microarray analysis, RNA aliquots of 4 controls and 4 affected samples were pooled to reduce the template needed and to exclude differences in expression due to individual variation and not related to BSP [5]. For qRT-PCR, individual RNA samples from the same animal and tissue samples were quantified as described above and used for the amplification.

\section{Microarray experiments}

Microarray slides, containing about $15 \mathrm{k}$ cDNA replicated twice, were obtained by ARK genomics (The Roslin Institute \& R(D)SVS, University of Edinburgh, Scotland). They were chosen for containing spots from a bovine brain library [6], a bovine monocyte library [7] and 979 control spots (landing lights, blank, salmon sperm, housekeeping genes). As stated in the previous section, the disease is likely to be linked to the nervous system $[3,4]$. Within each slide all spots are printed in duplicate; the experiment included two technical replicates; in each replicate two slides were duplicated in a dye-swap experiment [8]. We subsequently obtained a total of 8 replicates per cDNA spot. Inverse transcription was realized by SuperScript Indirect cDNA Labelling System (Invitrogen). Fluorescently-labeledcRNA was prepared using the 3DNA Array $900 \mathrm{MPX}$ Cy3/Cy5 Kit (Genisphere), according to the manufacturer's protocol. Pooled cDNA probes of 4 control and 4 affected animals were hybridised onto each bovine cDNA slide, according to Genisphere's instructions. In short, $2 \mu \mathrm{g}$ of total RNA was reverse transcribed using RT dT primer. Then, the cDNA and the fluorescent 3DNA reagent were hybridized to the microarray in succession. The fluorescent 3DNA reagent ( $\mathrm{Cy} 3$ and $\mathrm{Cy} 5$ ) hybridize to the cDNA by a "capture sequence" complementary to a sequence on the 5' end of the RT primer. Hybridization was performed at $60^{\circ} \mathrm{C}$ for 16 hours in a hybridization oven with shaking. Upon hybridization, microarrays were washed and dried according to the Genisphere's instructions and fluorescence measurements were performed using a ScanArrayLite (Perkin Elmer) laser scanner.

\section{Quantitative real time PCR}

RNA from the same animal and tissue samples were used to validate the microarray data. $1 \mu \mathrm{g}$ of total RNA from affected and control samples was reverse transcribed into cDNA using a blend of oligo-dT and random hexanucleotides and the QuantiscriptReverse Transcriptase (Quiagen). cDNA was transcribed in pools, using two control and two affected samples. Before making the qRT-PCR, a PCR was performed on all cDNA samples to assess the quality of the cDNA. A standard curve was generated using serial dilutions of the cDNA to calculate the efficiency of amplification. Real-time quantitative PCR was set up for three genes (ATP6V01, S100A12 and BCL2L1). Primer pairs, designed using primer3 [9], are listed in Additional file 1: Table S1 and are derived from publically available bovine ESTs. qRT-PCR was performed with the Brilliant II SYBR Green qRT-PCR kit (Stratagene, Agilent technologies) and using a Stratagene Mx3005P (Stratagene). Amplification results of affected samples were calibrated against those of controls to obtain the differences in gene expression. All results were normalized to $ß$-actin. Three biological replicates and two technical replicates were performed for each gene investigated.

\section{Polymerase chain reaction (PCR) conditions and sequence analysis}

PCR primers for ATP2A1/SERCA and SLC6A5 (Additional file 1: Table S1) were designed using primer3 [9] from the sequences available in Genbank (ATP2A1 NC_007326.4; SLC6A5 NC_007330.4) to amplify genomic fragments including mutations in the exons 6 and 16 for ATP2A1 and in exons 3 and 4 for SLC6A5. Each polymerase chain reaction (PCR) was performed in a total volume of $20 \mu \mathrm{l}$ containing $20 \mathrm{ng}$ of genomic DNA, $1.0 \mathrm{pMol}$ of each primer, $10 \mu \mathrm{l}$ of BioMix (Bioline) composed by BIOTAQDNA Polymerase and $2 \mathrm{mM}$ of dNTPs, on a PTC-100TM Peltier Thermal Cycler (MJ Research). A 5 minutes denaturation step was followed by 34 cycles of denaturation at $94^{\circ} \mathrm{C}$ (30 sec), annealing at $59^{\circ} \mathrm{C}(30 \mathrm{sec})$ and extension at $72^{\circ} \mathrm{C}$ (1 min); the final extension step was carried out at $72^{\circ} \mathrm{C}$ for 
5 minutes. PCR products were purified through ExoSap-IT (USB Corporation) to remove residual primers and dNTPs and used as templates for forward and reverse sequencing reactions. Sequencing was performed using a ceq8800 sequencer using DTCS QuickStart Kit and purifying with AgencourtCleanSEQ 96 (Beckman Coulter), according to manufacturer instructions. Sequences were aligned with Bioedit software [10].

\section{Data analysis}

Images were obtained by a ScanArrayLite (Perkin Elmer) laser scanner using Spotfinder software (TIGR). cDNA spots were automatically segmented, total foreground and background intensities of the two dyes were calculated for each spot. The spots were flagged by the software when they exhibited poor hybridization signals or when they were saturated. Spots with signal to background ratio below 1.5 were filtered out, together with flagged spots. Data systematic bias was removed by applying the dye-swap normalization $[8,11]$ that uses the reverse labelling in the microarray replicates and the lowness normalization [12,13]. The subtraction of the local spot background signal from the foreground signal was done according to the method developed by Scharpf and coauthors [14]. To establish the significance of the differential expression for each probe the t-test, was used, correcting p-values for multiple tests [15]. Finally, only genes with absolute value of the fold change at least 2.0 and a p-value $<0.05$ were considered.

KEGG pathways were retrieved for all slide genes [16-18].

Real Time data were analysed using the accompanying MxPro software (Stratagene). Relative expression of each gene for each sample was calculated by comparing $\mathrm{Ct}$ values of the target gene with $\mathrm{Ct}$ values of the $\beta$-actin constitutive gene product. T-test was performed in order to assess the statistical significance of the RT-PCR results.

\section{Functional analysis}

Functional analysis of gene lists was performed using the set of web-based functional annotation tools DAVID v6.7 $[19,20]$. The clustering tool was first used to check slide genes coverage and then to compare DEG pathways with the genes spotted on the slide. Furthermore hypergeometric test was computed to compare distribution in C1 class of KEGG pathways with genes spotted on slide. Then, DAVID tool was used to look for functional enrichment for genes over- and under-expressed more than two-fold in our samples. The statistical significance of the enrichment for the KEGG pathways of interest was computed by DAVID using the Fisher Exact test. KEGG pathway was selected as the functional annotation category for these analysis, assuming minimum number of genes for the corresponding C3 term (Count
Threshold) $=2$ and maximum EASE Score (modified Fisher P-value Threshold) $=0.005$ for enrichment analysis, and $\mathrm{CT}=1$ and $\mathrm{PT}=1$ for DEGs versus total genes on slide.

\section{Results}

\section{Differentially expressed genes}

To identify genes possibly involved in BSP development, we performed an experiment using a bovine cDNA microarray by hybridising cDNA of affected and control Romagnola samples. Differentially Expressed Genes (DEGs) were identified using t-test statistics. A p-value $<0.05$, corrected for multiple tests, and an absolute Fold Change value $(|F C|) \geq 2.0$ were used as criteria for the identification of DEGs. After filtering, 268 genes were found significantly over/under expressed in affected animals versus healthy controls; DEGs were annotated on Btau_4.0 version of the bovine genome, see Additional file 2: Table S2. The search in genomic databases was repeated several times during manuscript preparation to include sequences recently added in NCBI. The data have been deposited in NCBI Gene Expression Omnibus (GEO, http://www.ncbi.nlm.nih.gov/geo/info/linking.html) and are accessible through GEO, series accession number GSE25243. To validate microarray results, the expression of three genes (ATP6V01, S100A12 and BCL2L1), significantly over-expressed in affected samples, were tested by Quantitative Real Time PCR (qRT-PCR). The qRT-PCR data confirmed that the genes were significantly overexpressed in affected with respect to control samples (Table 1).

In the affected samples we observed a over-expression of the following genes: ATP6VOE1 which is involved in Oxidative Phosphorylatin pathway (FC 81.25); CATHL1 (FC 21.65) which is linked to Organismal Systems and Infectious Diseases pathway; the calcium binding protein S100A12 (FC 23.71) which is involved in the Calcium Signalling pathway; the HIST2H2AC (FC 5.90) which is involved in the Immune System Disease class; and the ATP/GTP binding protein-like gene AGBL5 (FC 3.67). Under-expression in affected samples was less marked (minimum value of FC -3.3). Among the under-expressed genes we observed the chromatin regulator SMARCA5 (FC -2.92); the transcription factor CREBZF (FC -2.83). The Rho GDP dissociation inhibitor (GDI) alpha (ARHGDIA) is under-expressed in affected samples

Table 1 Comparison of microarray and qRT-PCR results

\begin{tabular}{|c|c|c|c|c|}
\hline \multirow[t]{2}{*}{ Gene } & \multirow{2}{*}{$\frac{\text { Microarray }}{F C}$} & \multicolumn{3}{|l|}{ qRT-PCR } \\
\hline & & $P$ value & $F C$ & $P$ value \\
\hline$B C L 2 L 1$ & 2.34 & 0.0377 & 10.24 & 0.00017 \\
\hline S100A12 & 23.71 & 0.0055 & 15.76 & 0.00022 \\
\hline ATP6V01 & 81.29 & 0.0008 & 6.30 & 0.01775 \\
\hline
\end{tabular}


(FC -2.185). Two neurotransmitter transporters (SLC41A3, FC 2.361; SLC25A20, FC -2.191) and one organic anion transporter of the solute carrier family (SLCO1A2, FC -2.414) resulted altered in affected animals. Moreover, in affected samples we observed the over-expression of GRINA (FC 1.97) and SLC6A9 (FC 1.9), two genes involved in glycinergic synaptic transmission. The GFAP gene, encoding for the glial fibrillary acidic protein, was also overexpressed in affected animals (FC 2.60). The NR4A2 (FC 3.06) gene, a nuclear receptor family protein associated with dopaminergic dysfunctions, was over-expressed in affected animals.

We investigated the distribution of the DEGs in the bovine genome (UMD3.1 version). All Bos taurus chromosomes (BTAs) harbour differentially expressed genes; and a $30 \%$ percentage of them, is found in chromosomes 2, 3, 5, 7 and 18. We found over- and under-expressed gene clusters in narrow regions on BTA3, BTA5, BTA18 BTA21 and BTA22. Anyway, we have computed the $x^{2}$ statistics and we have not found any significant clustering of DEGs in these specific regions.

\section{Gene expression and KEGG analysis}

The Kyoto Encyclopedia of Genes and Genomes (KEGG) database was used to link microarray results to KEGG pathways to their relative $\mathrm{C} 1, \mathrm{C} 2$ and $\mathrm{C} 3$ classes (Table 2). Of the 268 DEGs in the microarray experiment, 195 were annotated sequences, linked to KEGG pathways and to their relative classes; 29 represented unidentified transcripts and 22 encoded for proteins with poorly known or unknown function. The NCBI webbased functional annotation tool DAVID v. 6.7 (Database for Annotation, Visualization and Integrated Discovery) was used to investigate functional associations of gene expression changes among differentially expressed genes [21].

This clustering tool was first used to check if all the spotted genes from the libraries were uniformly scattered across functional classes, showing a good representation of KEGG Pathways C1 class distribution. The frequency of all genes on the slide and of DEGs (Figure 1) showed that, in KEGG C1 class, the two distributions are significantly independent $(\mathrm{P}<0.001)$.

DAVID was used to analyse genes more than two-fold over- and under-expressed in our samples. Significant functional clustering of affected animals versus healthy controls in KEGG pathways is presented in Table 2. The 109 over-expressed genes belong to Cell Communication, Signaling Molecules and Interaction, Signal Transduction, Cancers and Nervous System C2 classes. Among the 86 genes under-expressed, the Neurodegenerative Diseases KEGG pathway C2 class results the only significant pathway in affected samples.

Two interesting C3 classes, the Amyotrophic Lateral Sclerosis (ALS) and the Neurotrophin signalling pathway are significantly enriched (see Functional analysis in Methods). The Amyotrophic Lateral Sclerosis belongs to the $\mathrm{C} 2$ class of Neurodegenerative Diseases and includes the under-expressed genes DERL1, NEFH and NEFL. The significant genes belonging to the Neurotrophin signalling pathway (a $\mathrm{C} 2$ class of Nervous System) are $A K T 2, A T F 4, B A D, C A M K 2 A$ and SH2B3. In addition, we observed under expression of NDUFB2 (FC -2.24) and TRAPPC4 (FC -2.82) genes which have a role in postsynaptic membrane trafficking and are differentially expressed in Parkinson's disease pathway [22]. The BAD, $N E F H, N E F L$ and DERL1 genes are also involved in Huntington's disease pathways. The Amyotrophic Lateral

Table 2 Significantly enriched KEGG pathway's classes for the 109 genes with over-expressed expression and for the 86 genes with under-expressed expression in affected animals versus healthy controls (Count threshold $=2$, EASE threshold $=0.05$ )

\begin{tabular}{|c|c|c|c|c|c|}
\hline & C1 class & C2 class & C3 class & Genes & $\mathrm{p}$-value \\
\hline & Cellular Processes & Cell Communication & Focal adhesion & $\begin{array}{l}\text { LOC518180, COL4A2, COL1A2, } \\
\text { PRKCG, LAMC2, BAD, THBS1, AKT2 }\end{array}$ & 0.0005 \\
\hline & Human Diseases & Cancers & Pathways in cancer & $\begin{array}{l}\text { LOC518180, DVL2, COL4A2, PRKCG, } \\
\text { LAMC2, BCL2L1, BAD, AKT2, DAPK1 }\end{array}$ & 0.0021 \\
\hline & Organismal Systems & Nervous System & $\begin{array}{l}\text { Neurotrophin } \\
\text { signaling pathway }\end{array}$ & $\begin{array}{l}\text { LOC518180, ATF4, SH2B3, BAD, } \\
\text { CAMK2A, AKT2 }\end{array}$ & 0.0021 \\
\hline \multirow[t]{3}{*}{ over-expressed } & $\begin{array}{l}\text { Environmental } \\
\text { Information } \\
\text { Processing }\end{array}$ & $\begin{array}{l}\text { Signaling Molecules } \\
\text { and Interaction }\end{array}$ & $\begin{array}{l}\text { ECM-receptor } \\
\text { interaction }\end{array}$ & $\begin{array}{l}\text { COL4A2, SDC1, COL1A2, LAMC2, } \\
\text { THBS1 }\end{array}$ & 0.0027 \\
\hline & $\begin{array}{l}\text { Environmental } \\
\text { Information } \\
\text { Processing }\end{array}$ & Signal Transduction & $\begin{array}{l}\text { ErbBsignaling } \\
\text { pathway }\end{array}$ & $\begin{array}{l}\text { LOC518180, PRKCG, BAD, CAMK2A, } \\
\text { AKT2 }\end{array}$ & 0.0031 \\
\hline & Human Diseases & Cancers & $\begin{array}{l}\text { Chronic myeloid } \\
\text { leukemia }\end{array}$ & LOC518180, BCL2L1, BAD, AKT2 & 0.020 \\
\hline under-expressed & Human Diseases & $\begin{array}{l}\text { Neurodegenerative } \\
\text { Diseases }\end{array}$ & $\begin{array}{l}\text { Amyotrophic lateral } \\
\text { sclerosis (ALS) }\end{array}$ & DERL1, NEFH, NEFL & 0.016 \\
\hline
\end{tabular}




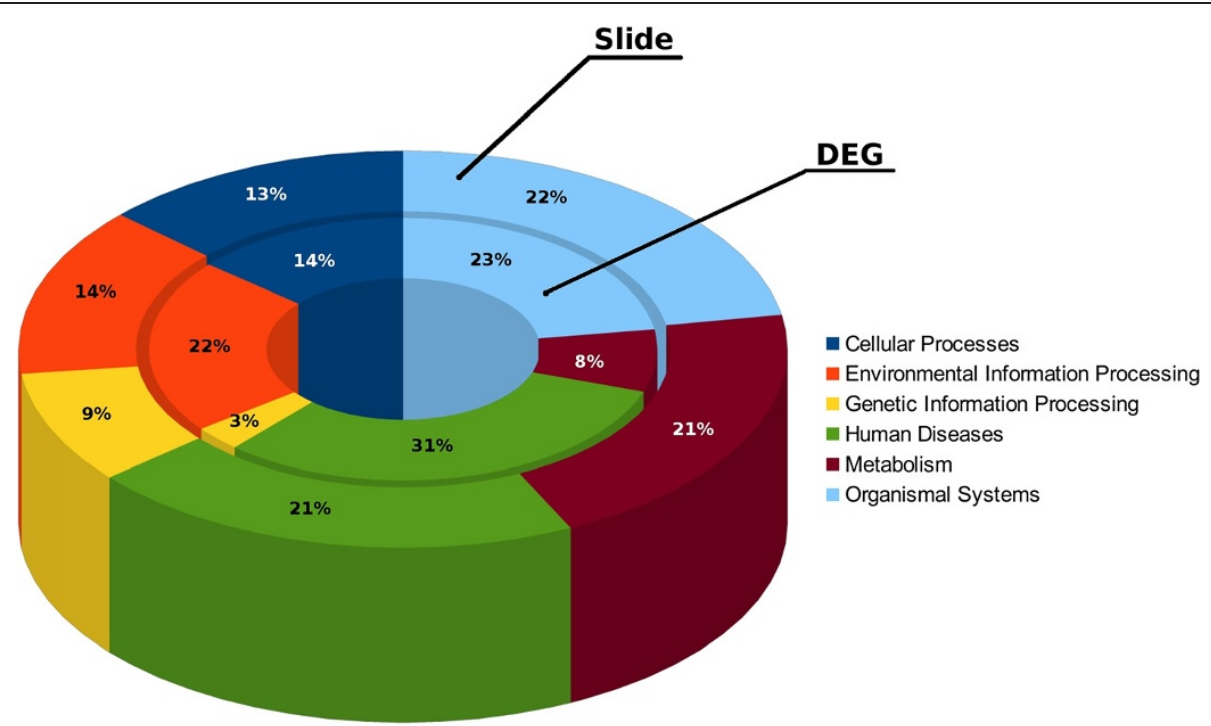

Figure 1 Gene clusters. Comparison of clustering between the 195 over- or under-expressed DEGs $(|F C| \geq 2)$ and the annotated genes on the slide, was assessed using the NCBI DAVID tool. C1 Class KEGG Pathway was selected as the annotation category for clustering.

Sclerosis, the Huntington's and the Parkinson's disease pathway pathologies present symptoms partially resembling to BSP's ones.

\section{ATP2A1/SERCA1 and SLC65 variants causative of BSP in} some cattle breeds are not involved in Romagnola BSP Recently, two genes were associated to other cattle diseases quite similar to spastic paresis: the ATP2A1/ $S E R C A 1$ gene which encodes for a calcium-transporting ATPase and the SLC6A5 gene which encodes a presynaptic glycine transporter. In Belgian Blue and in Chianina cattle breeds, the ATP2A1/SERCA1 gene was found to be implicated in the Congenital Muscular Dystonia 1 (CMD1, a disorder of muscle function caused by defects in the $\mathrm{Ca}^{2+}$ pump) and in the Congenital Pseudomyotonia [23-26]; while the SLC6A5 gene was found to be linked to the Congenital Muscular Dystonia 2 (CMD2) [23]. Since in the cDNA microarray we used, these genes were not included, we sequenced regions harbouring the polymorphic sites in the exons 6 and 16 of ATP2A1 [26] and in the exons 3 and 4 of SLC6A5 [23]. Both affected and control samples were monomorphic at the examined sites, therefore we can exclude that BSP in Romagnola was caused by the described mutations leading to CMD1 or CMD2 in Chianina and Belgian Blue breeds.

\section{Discussion}

The identification of causative genes associated with a disease is a complex task requiring gathering of genomewide information. The assessment of the expression of thousands of genes simultaneously may pinpoint the metabolic pathways affected by causative mutation(s) in order to focus on a small set of target genes.

We have tried to assess the metabolic pathways affected by the spastic paresis in Romagnola cattle breed, which presents this disease at quite a high frequency [2], using microarrays. The cDNA microarray we used in this study contains a brain library and, even if carrying an incomplete transcriptome representation, it has proven to be a valuable tool allowing us to add useful and new information to a poorly studied disease. Today, it is possible to prepare custom microarrays [27], while direct sequencing of transcripts by high-throughput sequencing technologies (RNA-Seq) would probably make possible to expand microarray investigation. However by using microarray tool, we analyzed $15 \mathrm{~K}$ genes with the aim to acquire knowledge of a genetic disease for which the current literature only provides scant results.

Results on metabolic pathways support an alteration of the Neurodegenerative Diseases and Nervous system C2 classes with the most frequently associated differentially expressed genes in the BSP (BAD, NEFH, NDUFB2, $D E R L 1, N E F L)$. Moreover, the ATP6VOE1 gene, encoding for a lysosomal $\mathrm{H}+$-transporting ATPase, showed the strongest signal (FC 81.29) on microarrays and together with NDUFB2, is involved in intracellular processes and is linked to Oxidative Phosphorylation pathway. PRKCG is a member of the protein kinase $C$ (PKC) gene family, whose members phosphorylate a wide variety of protein targets and are known to be involved in diverse cellular signalling pathways. Defects in this protein have been associated with neurodegenerative disorder spinocerebellar ataxia-14 [28].

Four calcium binding proteins involved in Calcium Signalling pathway, S100A12, S100A11, S100A8 and 
STK25, were weakly over-expressed in the affected animals. In Chianina cattle, a missense mutation in exon 6 (c.491G > A) of the bovine ATP2A1/SERCA1 gene, was implicated in Congenital Pseudomyotonia [24,25], a disease very similar to BSP and paralleled to human Brody disease by Drögemüller and collaborators, [26]. The same gene has been implicated also in Pseudomyotonia in Dutch Improved Red and White cross-breed [29]. We tested this mutation in our diseased animals and we did not find any carrier nevertheless Congenital Pseudomyotonia shares many symptoms with BSP. Therefore, even if BSP does not result associated to the mutations causing Congenital Pseudomyotonia reported in other cattle breeds, our data suggest the involvement of the calcium signalling proteins and two C3 classes, the Neurotrophin signalling pathway and Amyotrophic lateral sclerosis.

Charlier and coll [23] identified a bovine disorder named CMD2, reminiscent of congenital myoclonus in Hereford cattle, and reported a mutation in the glycine transporter GlyT2 (SLC6A5) gene already associated to human hyperexplexia [30]. Recently, SLC6A5 was also associated to hyperexplexia in Irish wolfhounds [31]. BSP shows many similarities with human hyperexplexia (OMIM 149400), an autosomal disease that can be caused by mutations in the genes encoding the alpha- 1 subunit of the glycine receptor (GLRA1), the presynaptic glycine transporter-2 (SLC6A5), the beta-subunit of the glycine receptor $(G L R B)$, the postsynaptic glycinergic proteins GPHN and ARHGEF9 [32-39]. Mutations in the latter gene cause hyperexplexia with epilepsy (OMIM 300607). In a previous study, we observed a number of mutations in GLRA1 and GLRB in Romagnola cattle [40], but none resulted significantly involved in the disease.

Our microarray results suggest also a defective glycinergic synaptic transmission in Romagnola BSP. The expression of the Rho GDP dissociation inhibitor (GDI) alpha (ARHGDIA) gene, of two neurotransmitter transporters (SLC41A3 and SLC25A20), of the organic anion transporter SLCO1A2 resulted altered in affected animals. In affected samples, we observed the overexpression of two genes involved in defective glycinergic synaptic transmission, GRINA and SLC6A9. This latter gene, encoding GlyT1, was recently implicated in defective glycinergic synaptic transmission in Zebrafish [41]. GFAP, encoding glial fibrillary acidic protein, linked to expression of the glutamate transporter Glt1 (SLC1A2) in Alexander disease, was also over-expressed in affected animals (FC 2.60). Mutations in NR4A2 (FC 3.06), a nuclear receptor family protein, have been associated with disorders related to dopaminergic dysfunction [42]. Most transporters involved in the drug disposal, characterized by broad substrate specificities and accepting structurally unrelated compounds, include members of SLC family.
The involvement of glycinergic proteins seems supported also at phenotypic level: the cholecystokinin (CCK) is involved in the neuroactive ligand-receptor interaction pathway. The release of CCK (ACBP) is linked to GABA and sensitive to clonazepam [43]. These features are found also in human hyperexplexia and are in agreement with the differential expression of some GABA neurotransmitter transporters of the solute carrier family emerging from our analysis.

\section{Conclusions}

BSP is a neuromuscular disorder, known since almost a century, not yet associated with a specific gene. Using microarrays, we identified several genes and pathways significantly linked to the development of BSP in Romagnola cattle breed. We identified genes belonging to two C3 classes, the Neurotrophin signalling pathway and the Amyotrophic Lateral Sclerosis.

Our results suggest also that the development of the disease is linked to a defective glycinergic synaptic transmission and an alteration of calcium signalling proteins. We reviewed the literature on the disease in order to compare published data with the KEGG categories identified by our microarray analysis. This will allow a gene targeted analysis aimed to identify BSPassociated polymorphisms in Romagnola. BSP shares many symptoms with other nervous diseases in this and other species, including humans. The study of the molecular mechanisms underpinning BSP in this and in other cattle breeds, as well as in other livestock species, may help to shed light also on neurodegenerative human diseases.

\section{Additional files}

Additional file 1: Table S1. Significantly differentially expressed genes with Fold change $|F C| \geq 2.0$.

Additional file 2: Table S2. List of primer pairs used for $q R T-P C R$ and PCR.

\section{Competing interests}

The authors declare that they have no competing interests.

\section{Authors' contributions}

LP: designed the study, carried out microarray experiments and drafted the manuscript. SBu and CEMG: performed microarray probes annotation and KEGG analysis. GP: performed statistical and chromosome position analyses. SBo and SBi: performed PCR and qRT-PCR experiments. AG: performed field survey and provided the samples used in microarray experiments. GC supervised statistical analysis. AV: participated in developing ideas, in supervision and revision of the manuscript. All authors read and approved the final manuscript.

\section{Acknowledgements}

We would like to thank Gabriella Porcai and Paolo Ciorba for technical assistance. We acknowledge CASPUR for computational resources.

\section{Author details}

${ }^{1}$ Department for Innovation in Biological, Agro-food and Forest systems (DIBAF), University of Tuscia, via S. Camillo de Lellis s.n.c, Viterbo, 01100, Italy. 
${ }^{2}$ CASPUR, (Inter-University Consortium for the Application of SuperComputing for Universities and Research), via dei Tizii 6, Rome 00185, Italy. ${ }^{3}$ Department of Veterinary Medical Sciences, University of Bologna, via Tolara di Sopra 50, 40064, Bologna, Ozzano Emilia, Italy.

Received: 20 May 2012 Accepted: 11 June 2013

Published: 19 June 2013

\section{References}

1. Ledoux M: Bovine spastic paresis: etiological hypotheses. Med Hypotheses 2001, 57:573-579.

2. Gentile A: La Paresi Spastica nel bovino di razza Romagnola. Atti Soc it Buiatria 2002, 34:191-198.

3. Chiocchetti R, Bombardi C, Grandis A, Mazzuoli G, Gentile A, Pisoni L, Joechler M, Lucchi ML: Cytoarchitecture, morphology, and lumbo sacral spinal cord projections of the red nucleus in cattle. Am J Vet Res 2006, 67:1662-1669.

4. Chiocchetti R, Grandis A, Bombardi C, Joechler M, Pisoni L, Gentile A: BulboPons-Mesencephalic Projections to the Lumbo-Sacral Spinal Cord in Healthy and Spastic Paresis-Affected Cattle: A Comparative Investigation. Vet Res Commun 2006, 30(1):175-177.

5. Kendziorski C, Irizarry RA, Chen KS, Haag JD, Gould MN: On the utility of pooling biological samples in microarray experiments. PNAS 2005, 102(12):4252-4257.

6. Jann OC, Aerts J, Jones M, Hastings N, Law A, McKay S, Marques E, Prasad A, Yu J, Moore SS, Floriot S, Mahe MF, Eggen A, Silveri L, Negrini R, Milanesi E, AimoneMarsan P, Valentini A, Marchitelli C, Savarese MC, Janitz M, Herwig R, Hennig S, Gorni C, Connor EE, Sonstegard TS, Smith T, Drogemuller C, Williams JL: A second generation radiation hybrid map to aid the assembly of the bovine genome sequence. BMC Genom 2006, 7(1):283.

7. McGuire K, Glass EJ: The expanding role of microarrays in the investigation of macrophage responses to pathogens. Vet Immunol Immunopathol 2005, 105(3-4):259-275.

8. Kerr MK, Churchill GA: Statistical design and the analysis of gene expression microarray data. Genet Res 2001, 77:123-128.

9. Rozen S, Skaletsky HJ: Primer 3. http://www.genome.wi.mit.edu/ genome software/other/primer3.html.

10. Hall TA: BioEdit: a user-friendly biological sequence alignment editor and analysis program for Windows 95/98/NT. Nucl Acids Symp Ser 1999, 41:95-98.

11. Peng X, Wood CL, Blalock EM, Chen KC, Landfield PW, Stromberg AJ: Statistical implications of pooling RNA samples for microarray experiments. BMC Bioinforma 2003, 4:26

12. Fang Y, Brass A, Hoyle DC, Hayes A, Bashein A, Oliver SG, Waddingtong D, Rattray M: A model-based analysis of microarray experimental error and normalisation. Nucleic Acids Res 2003, 31:e96.

13. Yang YH, Dudoit S, Luu P, Speed TP: Normalization for CDNAmicroarray data. In Microarrays: optical technologies and informatics, Society for Optical Engineering. Edited by Bittner M, Chen Y, Dorsel A, Dougherty ER, San Jose CA. 2001:41-152.

14. Scharpf RB, labocuzio-Donahue CA, Sneddon JB, Parmigiani G: When one should substract background fluorescence in two color microarrays? Biostatistics 2007, 8:695-707.

15. Benjamini $Y$, Hochberg $Y$ : Controlling the false discovery rate: a practical and powerful approach to multiple testing. J R Stat Soc 1995, 57:289-300.

16. Kanehisa M, Goto S: KEGG: Kyoto Encyclopedia of Genes and Genomes. Nucleic Acids Res 2000, 28:27-30.

17. Kanehisa M, Araki M, Goto S, Hattori M, Hirakawa M, Itoh M, Katayama T, Kawashima S, Okuda S, Tokimatsu T, Yamanishi Y: KEGG for linking genomes to life and the environment. Nucleic Acids Res 2008, 36:D480-D484.

18. Khatri P, Draghici S: Ontological analysis of gene expression data: Current tools, limitations, and open problems. Bioinformatics 2005, 21:3587-3595.

19. Huang DW, Sherman BT, Lempicki RA: Systematic and integrative analysis of large gene lists using DAVID Bioinformatics Resources. Nat Protoc 2009, 4(1):44-57.

20. Huang DW, Sherman BT, Lempicki RA: Bioinformatics enrichment tools: paths toward the comprehensive functional analysis of large gene lists. Nucleic Acids Res 2009, 37(1):1-13.

21. Dennis G Jr, Sherman BT, Hosack DA, Yang J, Gao W, Lane HC, Lempicki RA: DAVID: Database for Annotation, Visualization, and Integrated Discovery. Genome Biol 2003, 4:P3.
22. Elstner $M$, Morris $C M$, Heim $K$, Lichtner $P$, Bender A, Mehta D, Schulte $C$, Sharma M, Hudson G, Goldwurm S, Giovanetti A, Zeviani M, Burn DJ, McKeith IG, Perry RH, Jaros E, Krüger R, Wichmann HE, Schreiber S, Campbell H, Wilson JF, Wright AF, Dunlop M, Pistis G, Toniolo D, Chinnery PF, Gasser T, Klopstock T, Meitinger T, Prokisch H, Turnbull DM: Single-cell expression profiling of dopaminergic neurons combined with association analysis identifies pyridoxal kinase as Parkinson's disease gene. Ann Neurol 2009, 66:792-798.

23. Charlier C, Coppieters W, Rollin F, Desmecht D, Agerholm JS, Cambisano N, Carta E, Dardano S, Dive M, Fasquelle C, Frennet JC, Hanset R, Hubin X, Jorgensen C, Karim L, Kent M, Harvey K, Pearce BR, Simon P, Tama N, Nie H, Vandeputte S, Lien S, Longeri M, Fredholm M, Harvey RJ, Georges M: Highly effective SNP-based association mapping and management of recessive defects in livestock. Nat Genet 2008, 40:449-454.

24. Sacchetto R, Testoni S, Gentile A, Damiani E, Rossi M, Liguori R, Drögemüller C, Mascarello F: A Defective SERCA1 Protein Is Responsible for Congenital Pseudomyotonia in Chianina Cattle. Am J Pathol 2009, 174(2):565-573.

25. Testoni S, Boni P, Gentile A: Congenital pseudomyotonia in Chianina cattle. Vet Rec 2008, 163:252

26. Drögemüller C, Drögemüller M, Leeb T, Mascarello F, Testoni S, Rossi M, Gentile A, Damiani E, Sacchetto R: Identification of a missense mutation in the bovine ATP2A1 gene in congenital pseudomyotonia of Chianina cattle: An animal model of human Brody disease. Genomics 2008, 92(6):474-477.

27. Pariset L, Chillemi G, Bongiorni S, Spica VR, Valentini A: High throughput transcriptomic analysis for species without known genomic DNA sequences. Rev New Biotechnol 2009, 25(5):272-279.

28. Seki T, Shimahara T, Yamamoto K, Abe N, Amano T, Adachi N, Takahashi H, Kashiwagi K, Saito N, Sakai N: Mutant gamma PKC found in spinocerebellar ataxia type 14 induces aggregate-independent maldevelopment of dendrites in primary cultured Purkinje cells. Neurobiol Dis 2009, 33(2):260-273.

29. Grünberg W, Sacchetto R, Wijnberg I, Neijenhuis K, Mascarello F, Damiani E, Drögemüller C: Pseudomyotonia, a muscle function disorder associated with an inherited ATP2A1 (SERCA1) defect in a Dutch Improved Red and White cross-breed calf. Neuromuscul Disord 2010, 20(7):467-470.

30. Eulenburg V, Becker K, Gomeza J, Schmitt B, Becker CM, Betz H: Mutations within the human GLYT2 (SLC6A5) gene associated with hyperekplexia. Biochem Biophys Res Commun 2006, 348(2):400-405.

31. Gill JL, Capper D, Vanbellinghen JF Chung SK, Higgins RJ, Rees MI, Shelton D, Harvey RJ: Startle disease in Irish wolfhounds associated with a microdeletion in the glycine transporter GlyT2 gene. Neurobiol Dis 2011, 43(1):184-189

32. Rees Ml, Andrew M, Jawad S, Owen MJ: Evidence for recessive as well as dominant forms of startle disease (hyperekplexia) caused by mutations in the alpha 1 subunit of the inhibitory glycine receptor. Hum Molec Genet 1994, 3:2175-2179.

33. Shiang R, Ryan SG, Zhu YZ, Hahn AF, O'Connell P, Wasmuth JJ: Mutations in the alpha 1 subunit of the inhibitory glycine receptor cause the dominant neurologic disorder, hyperekplexia. Nat Genet 1993, 5:351-357.

34. Milani N, Mulhardt C, Weber RG, Lichter P, Kioschis P, Poustka A, Becker CM: The human glycine receptor beta subunit gene (GLRB): structure, refined chromosomal localization, and population polymorphism. Genomics 1998, 50:341-345.

35. Pierce KD, Handford CA, Morris R, Vafa B, Dennis JA, Healy PJ, Schofield PR: A nonsense mutation in the alpha1 subunit of the inhibitory glycine receptor associated with bovine myoclonus. Mol Cell Neurosci 2001, 17(2):354-363.

36. Rees MI, Lewis TM, Kwok JBJ, Mortier GR, Govaert P, Snell RG, Schofield PR, Owen MJ: Hyperekplexia associated with compound heterozygote mutations in the beta-subunit of the human inhibitory glycine receptor (GLRB). Hum Molec Genet 2002, 11:853-860.

37. Rees MI, Harvey K, Ward H, White JH, Evans L, Duguid IC, Hsu CCH, Coleman SL, Miller J, Baer K, Waldvogel HJ, Gibbon F, Smart TG, Owen MJ, Harvey RJ, Snell RG: Isoform heterogeneity of the human gephyrin gene (GPHN), binding domains to the glycine receptor, and mutation analysis in hyperekplexia. J Biol Chem 2003, 278:24688-24696.

38. Rees MI, Harvey K, Pearce BR, Chung SK, Duguid IC, Thomas P, Beatty S, Graham GE, Armstrong L, Shiang R, Abbott K, Zuberi SM, Stephenson JBP, Owen MJ, Tijssen MAJ, Van den Maagdenberg AMJM, Smart TG, Supplisson S, Harvey RJ: Mutations in the gene encoding GlyT2 (SLC6A5) define a presynaptic component of human startle disease. Nat Genet 2006 , 38:801-806. 
39. Harvey RJ, Topf M, Harvey K: The genetics of hyperekplexia: more than startle! Trends Genet 2008, 24(9):439-447.

40. Pariset L, Cappuccio I, Savarese MC, Gentile A, Filippini F, Ajmone-Marsan P, Valentini A: Analysis of candidate genes for bovine spastic paresis. Ital J Anim Sci 2007, 6(1):S183.

41. Hirata H, Carta E, Yamanaka I, Harvey RJ, Kuwada JY: Defective Glycinergic Synaptic Transmission in Zebrafish Motility Mutants. Mol Neurosci 2010, 2:26.

42. Le W, Xu P, Jankovic J, Jiang H, Appel SH, Smith RG, Vassilatis DK: Mutations in NR4A2 associated with familial Parkinson disease. Nat Genet 2003, 33:85-89.

43. Ryan SG, Sherman SL, Terry JC, Sparkes RS, Torres MC, Mackey RW: Startle disease, or hyperekplexia: response to clonazepam and assignment of the gene (STHE) to chromosome 5q by linkage analysis. Ann Neurol 1992 31:663-668.

doi:10.1186/1746-6148-9-122

Cite this article as: Pariset et al:: Microarray gene expression profiling of neural tissues in bovine spastic paresis. BMC Veterinary Research 2013 9:122.

\section{Submit your next manuscript to BioMed Central and take full advantage of:}

- Convenient online submission

- Thorough peer review

- No space constraints or color figure charges

- Immediate publication on acceptance

- Inclusion in PubMed, CAS, Scopus and Google Scholar

- Research which is freely available for redistribution 